\title{
REGIONAL POVERTY LEVELS IN THE EUROPEAN UNION: A SPATIAL ECONOMETRIC APPROACH ${ }^{1}$
}

The main objective of this study is to analyze the most important determinants of monetary poverty (at the macro-level) in the European Union, taking into account the effects of regional spillovers. Regression analyses of spatial data in the period 2007-2009, i.e. the pre-crisis and crisis years are performed in order to compare the size of the impact of the selected variables on poverty levels. In the study, a spatial Durbin model $(S D M)$ is employed and the sample includes 187 EU regions. In order to quantify the impacts of the explanatory variables, scalar summary measures are used (the average direct impacts, as well as the indirect and total impacts of income, are negative).

Keywords: monetary poverty, spatial Durbin model, regional spillovers, European Union

\footnotetext{
${ }^{1}$ C Zelinsky T. Text. 2014
}

ЭКОНОМИКА РЕГИОНА № 2 (2014) 


\section{Introduction}

With respect to the economic crisis and high unemployment levels, living conditions, poverty and inequality research attracts attention from researchers from different disciplines. The consequences of the economic crisis include the widening of the gap between rich and poor and the worsening living conditions (not only) of the poorest. In this paper, we focus on the regional poverty levels in the European Union, where over 80 million EU citizens are estimated to be poor (based on the monetary concept). In terms of poverty research nowadays, the researchers focus on the developing countries, as well as the developed countries (see e. g. [1], [2], [3], [4]).

The assessment of well-being for poverty analyses is usually based on two main conceptual approaches: the welfarist approach and the non-welfarist approach [5]. The welfarist approach assumes that individuals are rational and able to make production and consumption choices that maximize their utility. A lack of command over commodities measured by low income or consumption is the working definition of poverty in terms of the welfarist conceptual approach [6]. The non-welfarist approach recognizes two basic concepts: the basic needs concept linked to A. K. Sen's [7] functioning's concept and the capabilities concept, also introduced by A. K. Sen [8]. The measurement of well-being following the welfarist approach is based on proxies, such as income, consumption or expenditure data, and following the non-welfarist approach it is based on proxies such as material deprivation [9].

Several analyses of poverty at the regional level in the European Union have been performed. Several papers investigate poverty and its regional aspects in the European Union (see e.g. [10], [11], [12], [13], [14], [15]). As a contribution to poverty research in the European Union at the regional level, the main objective of this study is to analyse the most important determinants of monetary poverty (at the macro-level) in the European Union, taking into account the effects of regional spillovers. Regression analyses of spatial data in the pre-crisis year of 2007 and the crisis years of $2008 / 2009$ are performed in order to compare the size of the impact of the selected variables. In this study, a spatial Durbin model (SDM) is employed and the sample includes $187 \mathrm{EU}$ regions. In order to quantify the impacts of the explanatory variables, scalar summary measures are used (the average direct impacts, as well as the indirect and total impacts, of income are negative). All the estimations, calculations and graphical outputs were performed in the R environment [16] using the li- braries spdep [17], rgdal [18], maptools [19] and shape [20].

\section{Description of the Model}

\subsection{The Spatial Durbin Model}

In this study, a spatial Durbin model (SDM), given by Eq. (1), is employed. The rationale behind this model is to incorporate the spatial effects working through the dependent variable and the spatial effects working through the explanatory variables.

$$
\mathbf{y}=\iota_{n} \alpha+\mathbf{X} \boldsymbol{\beta}+\rho \mathbf{W y}+\mathbf{W} \mathbf{X} \gamma+\varepsilon
$$

where $\mathbf{y}-$ is an $n$-by- 1 vector of observations of at-risk-of-poverty rates (natural logarithms are used); $\iota_{n}$ - is an $n$-by- 1 vector of ones with the associated scalar parameter $\alpha ; \mathbf{X}-$ is an $n$-by- $q$ matrix of observations of the four explanatory variables (natural logarithms of all the variables are used) with the associated vector parameter $\beta ; \mathbf{W}-$ is an $n$-by- $n$ non-stochastic spatial weight matrix specifying the spatial dependence among regions. In accordance with [21], $\mathbf{W}$ is based on the nearest neighbours with $k=6$. When region $j$ is a neighbour of region $i, W_{i j}=1$, and $W_{i j}=0$ otherwise. The diagonal elements of $\mathrm{W}$ are set to zero by convention. W is row-standardised, which ensures that all the weights are between zero and one, while the sum of the weights in each row is one (as six nearest neighbours are used, the spatial weights equal $1 / 6)$; $\mathbf{W y}-$ is an $n$-by- 1 spatial lag vector of y with an associated scalar spatial dependence parameter (the parameter of the first-order spatial autoregressive process) $\rho$, and is assumed to lie within the interval $(-1,1)$. In our model, we assume that $0<\rho<1$, which indicates that the regional at-risk-of-poverty rates are positively related to the at-risk-of-poverty rates in neighbouring regions; $\mathbf{W X}-$ is an $n$-by- $q$ matrix of the spatially lagged explanatory variables with associated vector parameter $\gamma ; \varepsilon-$ is an $n$-by- 1 normally distributed, constant variance disturbance term, $\varepsilon \sim N\left(0, \sigma_{\varepsilon}^{2} I_{n}\right)$.

2.2. Observation Units and Description of the Data

The sample includes 187 observations of complete data sets of regions at the NUTS-2 level (in a few cases at the NUTS-1 level) of 20 European countries: Austria (9 NUTS- 2 regions), Belgium (3 NUTS-1 regions), Bulgaria (6 NUTS- 2 regions), the Czech Republic (8 NUTS-2 regions), Germany (35 NUTS-2 regions), Denmark (5 NUTS-2 regions), Greece (4 NUTS-1 regions), Spain (19 NUTS-2 regions), France (22 NUTS-2 regions), Hungary (3 NUTS- 1 regions), Ireland (2 NUTS- 2 regions), Italy (11 NUTS-2 regions), the Netherlands (12 NUTS-2 
regions), Norway (7 NUTS-2 regions), Poland (6 NUTS-1 regions), Romania (8 NUTS-2 regions), Sweden (8 NUTS-2 regions), Slovenia (2 NUTS-2 regions), Slovakia (4 NUTS-2 regions) and the United Kingdom (12 NUTS-1 regions).

The at-risk-of-poverty rate as the dependent variable and four explanatory variables (disposable per capita income, long-term unemployment rate, education level and population density) are employed in the survey. In order to assess the potential influence of the economic crisis on the estimated impacts, all the variables refer to the observation years 2007, 2008 and 2009 (complete data sets were not available for 2010 and 2011).

The at-risk-of-poverty rate [arop] (after social transfers) is defined as the share of persons with an equivalised disposable income below the risk-of-poverty line, which is set at $60 \%$ of the national median equivalised disposable income after social transfers. The disposable income is defined as the gross income less income tax, regular taxes on wealth and compulsory social insurance contributions, while the gross income is the total monetary and non-monetary income received by the household over a specified income reference period. Income is measured at the household level, and in order to gain the equivalised disposable in- come, the total disposable income of a household has to be divided by the equivalised household size according to the modified OECD scale (giving a weight of 1.0 to the first adult, 0.5 to other persons aged 14 or over and 0.3 to each child younger than 14).

Figure 1 depicts the distribution of the at-riskof-poverty rate across the EU regions. It is obvious that regions with a high at-risk-of-poverty rate are concentrated in the eastern and southern part of the European Union. The boxplots further indicate that the mean value of the poverty rate increased between 2007 and 2009, but the notches measuring the significance of the difference between the two medians indicate that the differences among the medians are not statistically significant.

The disposable per capita income [income] is the total income of a household, after tax and other deductions, that is available for spending or saving, divided by the number of household members. The disposable per capita income is measured in terms of the purchasing power standard based on the final consumption per inhabitant.

The long-term unemployment rate [unempl] is the share of people who are out of work and have been actively seeking employment for at least a year, and is measured as a percentage.
AROP 07

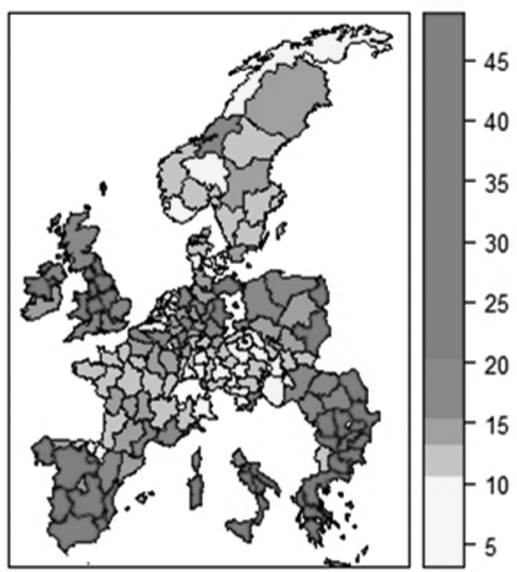

AROP 08

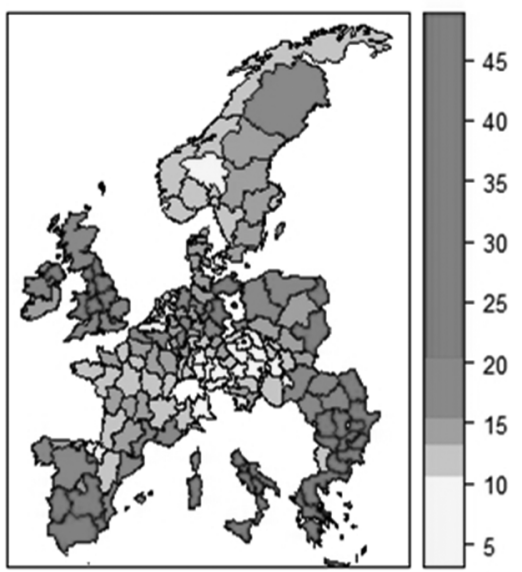

AROP 09

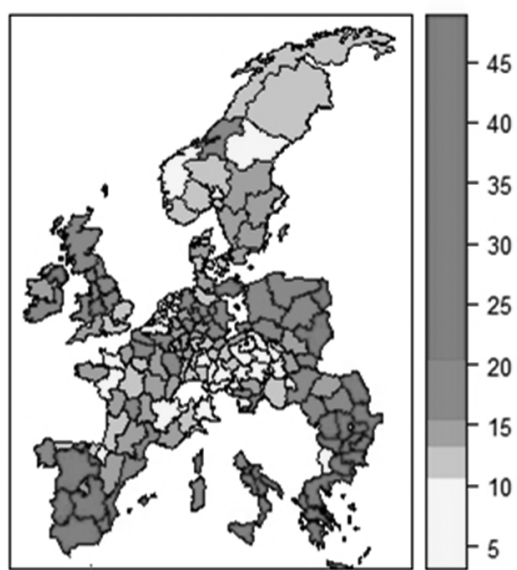

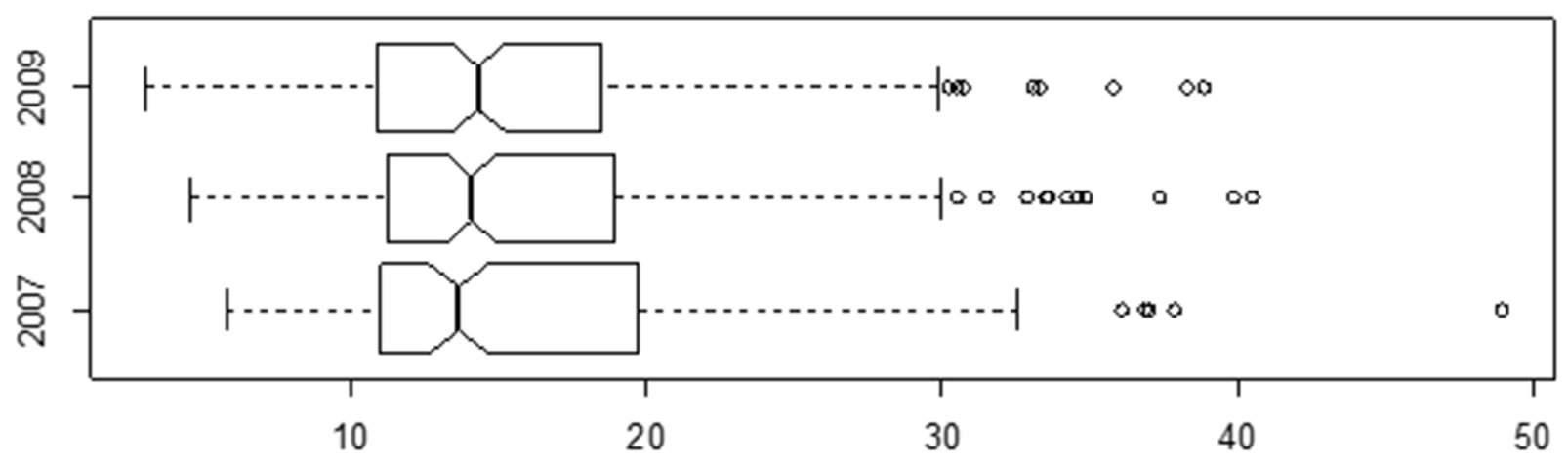

Source: own construction, based on Eurostat data

Fig. 1. Distribution of the at-risk-of-poverty rate 
Disposable income, EUR PPS

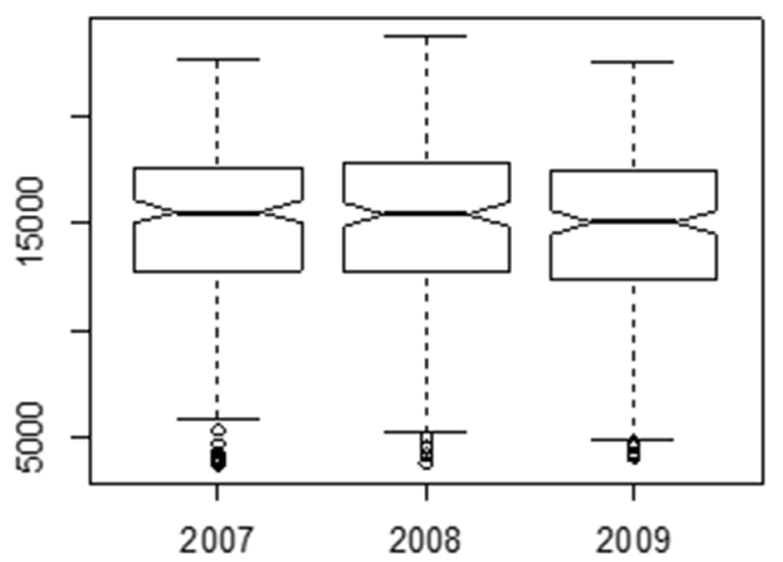

Education

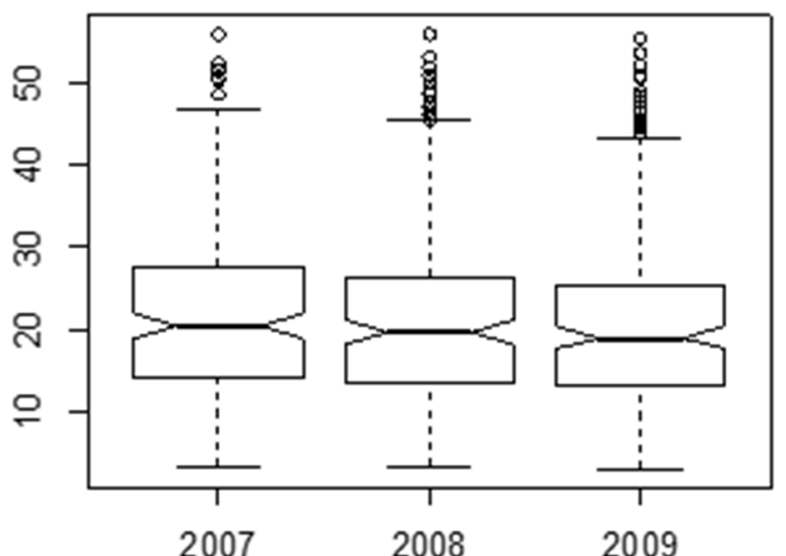

2007

2008

2009

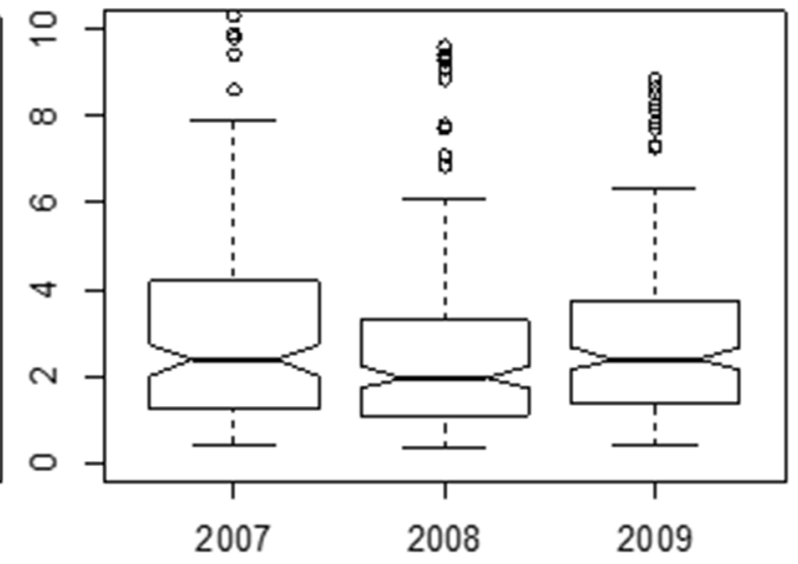

Population density

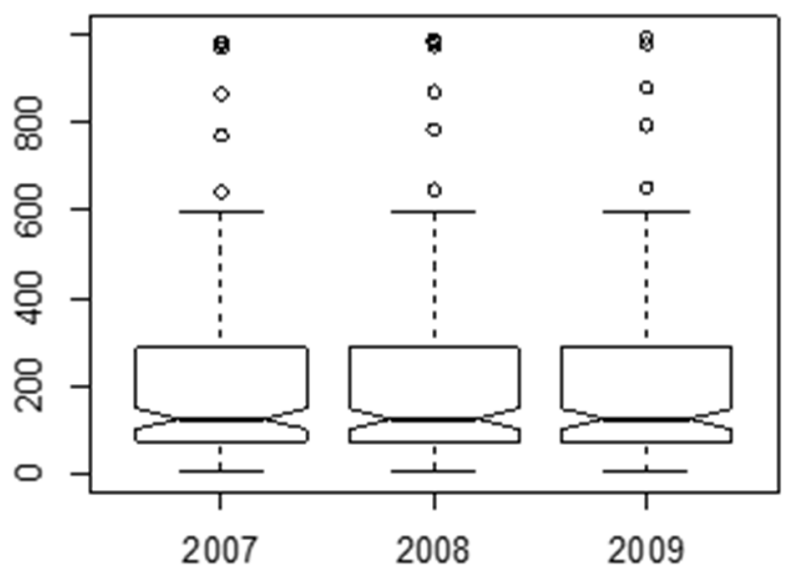

Source: own construction, based on Eurostat data

Fig. 2. Distribution of the explanatory variables

As a proxy for the education level [edu], the share of persons aged 25-64 with pre-primary, primary or lower secondary education attainment is used. The category pre-primary, primary or lower secondary education refers to the ISCED-97 levels $0-2$.

The population density [density] is measured in terms of the number of inhabitants per square kilometre.

Figure 2 depicts the distribution of the explanatory variables between 2007 and 2009. The notched boxplots indicate that there are no statistical differences in the medians among the years; on the other hand, however, the long-term unemployment rate distribution indicates a decrease in the median long-term unemployment rate between 2007 and 2008 followed by an increase between 2008 and 2009.

The spatial autocorrelation of the variables was further investigated (see Table 1). All the variables except for population density are significantly positively spatially autocorrelated, i.e. sim- ilar values occur near one another. Moran's I statistics (for the statistically significant spatial autocorrelation) range between 0.3995 and 0.7678 .

In the proposed regression model, the at-riskof-poverty rate in region $i$ (denoted by $y_{i}$ ) depends on the poverty rates in the neighbouring regions (as defined in the spatial weight matrix $\mathbf{W}$ ) captured by the spatial lag variable $\mathbf{W}_{i} \mathbf{y}$, where $\mathbf{W}_{i}$ is the $i^{\text {th }}$ row of the spatial weight matrix $\mathbf{W}$. It further depends on the own-region levels of disposable per capita income, long-term unemployment rate, education and population density (given by the $i^{\text {th }}$ row of matrix $\mathbf{X}$ ) as well as the levels of disposable per capita income, long-term unemployment rate, education and population density in the neighbouring regions, represented by $\mathbf{W}_{i} \mathbf{X}$.

Taking into account the relationships among the neighbouring regions, a change in the $q^{\text {th }}$ variable in region $i$ has not only a direct impact on the at-risk-of-poverty rate of this region, but also an indirect impact on other regions $j \neq i$. The estimated model will be discussed in terms of direct, 
Spatial autocorrelation of the variables (Moran's I statistic)

\begin{tabular}{|c|c|c|c|}
\hline Variable & $\mathbf{2 0 0 7}$ & $\mathbf{2 0 0 8}$ & $\mathbf{2 0 0 9}$ \\
\hline \multirow{2}{*}{ arop } & $\begin{array}{c}0.5578^{* * *} \\
(<0.0001)\end{array}$ & $\begin{array}{c}0.5898^{* * *} \\
(<0.0001)\end{array}$ & $\begin{array}{c}0.5128^{* * *} \\
(<0.0001)\end{array}$ \\
\hline \multirow{2}{*}{ density } & 0.0368 & 0.0367 & 0.0368 \\
& $(0.2489)$ & $(0.2498)$ & $0.2490)$ \\
\hline \multirow{2}{*}{ edu } & $0.7672^{* * *}$ & $0.7678^{* * *}$ & $(<0.0001)$ \\
\hline \multirow{2}{*}{ income } & $(<0.0001)$ & $0.7333^{* * *}$ & $0.7436^{* * *}$ \\
& $0.7579^{* * *}$ & $(<0.0001)$ & $(<0.0001)$ \\
\hline \multirow{2}{*}{ unempl } & $(<0.0001)$ & $0.3995^{* * *}$ & $0.4433^{* * *}$ \\
& $0.4165^{* * *}$ & $(<0.0001)$ & $(<0.0001)$ \\
\hline
\end{tabular}

Signif. codes: $00^{(* *)} 0.001^{(* *)} 0.01^{(*)} 0.05^{\text {‘ }}$ ' $0.1^{\text {' ’ } 1}$

Source: own construction, based on Eurostat data

indirect and total effects, as proposed by [22], and the interpretation follows [23].

\section{Results}

The estimation results of the spatial Durbin model and the quantification of the explanatory variables on the at-risk-of-poverty rates are presented in this section. In order to quantify the impacts of the explanatory variables, the scalar summary measures suggested by [22] are used.

\subsection{Model Estimation}

In order to discriminate between the unrestricted spatial Durbin model and the spatial error model, i.e. between substantive and residual dependence, a likelihood ratio test is used. A likelihood ratio test rejects the null hypothesis of a spatial error model specification (test statistics: 507.1 (2007 model), 374.6 (2008 model) and 420.9 (2009 model) with the corresponding p-values: $<0.0001)$. This supports our belief that the spatial externalities are substantive rather than random. The estimated spatial autoregressive parameters $\left(\hat{\rho}_{2007}=0.6685, \hat{\rho}_{2008}=0.6900\right.$ and $\left.\hat{\rho}_{2009}=0.4648\right)$ provide evidence of significant spatial effects working through the dependent variable. A variance inflation factor measure was used to check for possible multicollinearity in the model.

In Table 2, we can see that three non-spatially lagged explanatory variables (education, disposable income and long-term unemployment) and two spatially lagged explanatory variables (education and long-term unemployment) are statistically significant. Taking into account that the quantification of the impacts of the explanatory variables is based on direct, indirect and total effects, as suggested by [22], the output in Table 2 is not of great importance for interpretation purposes regarding the impact of the explanatory variables.
As pointed out by [23], estimates associated with spatially lagged variables are often incorrectly interpreted as measures of the size and significance of indirect impacts in spatial regression models. In the case of our model, the indirect effects of education and long-term unemployment would be interpreted incorrectly (both spatially lagged variables are statistically significant, but the indirect impacts are statistically insignificant according to Table 3).

\subsection{Impacts' Estimates}

This section focuses on the interpretation of the estimated model in terms of the direct, indirect and total effects (Table 3 ). The average direct impacts, or in other words the impact of changes in the $i^{\text {th }}$ observation of $x_{q}$, denoted as $x_{i q}$, on $y_{i}$ are similar in spirit to typical regression coefficient interpretations [22]. The direct impacts include feedback influences arising as a result of the impacts passing through neighbours and back to the observation itself [24].

The average indirect impacts represent the total impact on the individual observation $y_{i}$ resulting from changing the $q^{\text {th }}$ explanatory variable by the same amount across all $n$ observations. On the other hand, the average indirect effects also represent impacts on an observation, i.e. how changes in all the observations influence a single observation $i$.

The average total impacts are represented by the sum of the average direct effects and the average indirect effects. If the values of the $q_{\text {th }}$ explanatory variable change by the same unit in all the regions, the value of the dependent variable will change by $(1-\rho)^{-1} \beta_{q}$ units. In other words, the average total impacts reflect how a one-percent change in the qth explanatory variable in all the regions influences the dependent variable in a typical (average) region. 
Estimated coefficients

\begin{tabular}{|c|c|c|c|}
\hline Variable & 2007 & 2008 & 2009 \\
\hline (Intercept) & $\begin{array}{l}1.7129^{* *} \\
(0.0032)\end{array}$ & $\begin{array}{l}1.6613^{* *} \\
(0.0042)\end{array}$ & $\begin{array}{l}2.5164^{* * *} \\
(0.0003)\end{array}$ \\
\hline $\log$ (density) & $\begin{array}{c}0.0040 \\
(0.8233) \\
\end{array}$ & $\begin{array}{l}-0.0042 \\
(0.7999)\end{array}$ & $\begin{array}{l}-0.0273 \\
(0.1519) \\
\end{array}$ \\
\hline $\log (e d u)$ & $\begin{array}{l}0.3011^{* * *} \\
(<0.0000)\end{array}$ & $\begin{array}{l}0.2272^{* * *} \\
(<0.0000)\end{array}$ & $\begin{array}{l}0.2619^{* * *} \\
(<0.0000)\end{array}$ \\
\hline $\log ($ income $)$ & $\begin{array}{l}-0.2429^{*} \\
(0.0110)\end{array}$ & $\begin{array}{c}-0.2519^{* *} \\
(0.0057)\end{array}$ & $\begin{array}{c}-0.3171^{* *} \\
(0.0046)\end{array}$ \\
\hline $\log ($ unempl $)$ & $\begin{array}{c}0.2796^{* * *} \\
(<0.0000)\end{array}$ & $\begin{array}{l}0.2712^{* * *} \\
(<0.0000)\end{array}$ & $\begin{array}{l}0.3258^{* * *} \\
(<0.0000)\end{array}$ \\
\hline lag.log(density) & $\begin{array}{c}0.0141 \\
(0.6370)\end{array}$ & $\begin{array}{c}0.0124 \\
(0.6545)\end{array}$ & $\begin{array}{c}0.0262 \\
(0.3908)\end{array}$ \\
\hline $\operatorname{lag} \cdot \log (\mathrm{edu})$ & $\begin{array}{c}0.1671^{*} \\
(0.0316) \\
\end{array}$ & $\begin{array}{l}-0.1188^{\bullet} \\
(0.0846)\end{array}$ & $\begin{array}{l}-0.1325^{\circ} \\
(0.0785)\end{array}$ \\
\hline lag.log(income) & $\begin{array}{c}0.1025 \\
(0.3454)\end{array}$ & $\begin{array}{c}0.1256 \\
(0.2248)\end{array}$ & $\begin{array}{c}0.1543 \\
(0.2153)\end{array}$ \\
\hline lag.log(unempl) & $\begin{array}{l}-0.2367^{* * *} \\
(<0.0000)\end{array}$ & $\begin{array}{l}-0.2221^{* * *} \\
(<0.0000)\end{array}$ & $\begin{array}{c}-0.2052^{* * *} \\
(0.0004)\end{array}$ \\
\hline Rho: & $\begin{array}{c}0.6685^{* * *} \\
(<0.0000)\end{array}$ & $\begin{array}{l}0.6900^{* * *} \\
(<0.0000)\end{array}$ & $\begin{array}{l}0.4648^{* * *} \\
(<0.0000)\end{array}$ \\
\hline Nagelkerke pseudo R2 & 0.6580 & 0.6746 & 0.5987 \\
\hline Log-Lik & 3.8436 & 12.3834 & -8.4727 \\
\hline
\end{tabular}

Signif. codes: $0{ }^{(* *)} 0.001^{(* *)} 0.01^{(*)} 0.05^{(\bullet)} 0.1$ ' 1

Source: own construction

Table 3

Estimated impacts

\begin{tabular}{|c|c|c|c|c|c|}
\hline \multicolumn{2}{|c|}{ Impacts } & $\log ($ density $)$ & $\log (\mathrm{edu})$ & $\log ($ income $)$ & $\log ($ unempl) \\
\hline \multirow{3}{*}{ Direct } & 2007 & $\begin{array}{c}0.0065 \\
(0.6861)\end{array}$ & $\begin{array}{l}0.3062^{* * *} \\
(0.0000)\end{array}$ & $\begin{array}{c}-0.2520^{* *} \\
(0.0057)\end{array}$ & $\begin{array}{l}0.2721^{* * *} \\
(0.0000)\end{array}$ \\
\hline & 2008 & $\begin{array}{r}-0.0027 \\
(0.9056) \\
\end{array}$ & $\begin{array}{l}0.2333^{* * *} \\
(0.0000)\end{array}$ & $\begin{array}{c}-0.2597^{* *} \\
(0.0033)\end{array}$ & $\begin{array}{l}0.2656^{* * *} \\
(0.0000)\end{array}$ \\
\hline & 2009 & $\begin{array}{l}-0.0262 \\
(0.1614) \\
\end{array}$ & $\begin{array}{l}0.2611^{* * *} \\
(0.0000)\end{array}$ & $\begin{array}{c}0.3166^{* *} \\
(0.0036)\end{array}$ & $\begin{array}{l}0.3216^{* * *} \\
(0.0000)\end{array}$ \\
\hline \multirow{3}{*}{ Indirect } & 2007 & $\begin{array}{c}0.0479 \\
(0.5100)\end{array}$ & $\begin{array}{c}0.0980 \\
(0.4621)\end{array}$ & $\begin{array}{l}-0.1718 \\
(0.3255)\end{array}$ & $\begin{array}{l}-0.1426 \\
(0.1765)\end{array}$ \\
\hline & 2008 & $\begin{array}{c}0.0291 \\
(0.7397) \\
\end{array}$ & $\begin{array}{c}0.1163 \\
(0.3548) \\
\end{array}$ & $\begin{array}{l}-0.1478 \\
(0.4698) \\
\end{array}$ & $\begin{array}{l}-0.1072 \\
(0.3289) \\
\end{array}$ \\
\hline & 2009 & $\begin{array}{c}0.0243 \\
(0.6365)\end{array}$ & $\begin{array}{l}-0.0193 \\
(0.8435) \\
\end{array}$ & $\begin{array}{c}0.0125 \\
(0.9196)\end{array}$ & $\begin{array}{l}-0.0963 \\
(0.2064)\end{array}$ \\
\hline \multirow{3}{*}{ Total } & 2007 & $\begin{array}{c}0.0544 \\
(0.4775) \\
\end{array}$ & $\begin{array}{l}0.4042^{* * *} \\
(0.0007)\end{array}$ & $\begin{array}{c}-0.4238^{*} \\
(0.0152)\end{array}$ & $\begin{array}{c}0.1295 \\
(0.2925) \\
\end{array}$ \\
\hline & 2008 & $\begin{array}{c}0.0264 \\
(0.7712) \\
\end{array}$ & $\begin{array}{l}0.3496^{* *} \\
(0.0027)\end{array}$ & $\begin{array}{c}-0.4075^{*} \\
(0.0360) \\
\end{array}$ & $\begin{array}{c}0.1584 \\
(0.1542) \\
\end{array}$ \\
\hline & 2009 & $\begin{array}{l}-0.0019 \\
(0.9695)\end{array}$ & $\begin{array}{l}0.2418^{* *} \\
(0.0013)\end{array}$ & $\begin{array}{c}0.3041^{\star *} \\
(0.0092)\end{array}$ & $\begin{array}{l}0.2253^{* *} \\
(0.0023)\end{array}$ \\
\hline
\end{tabular}

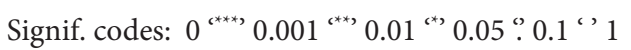

Source: own construction

\section{Discussion and Conclusions}

As expected, the average direct impact of income is negative, the impact of unemployment is positive and the impact of education is positive as well. If the median income increases in region $i$, the poverty rate is likely to decrease in the same region. On the other hand, a rise in the long-term unemployment rate in a region i results in an in- 
crease in the poverty rate in the same region, and the same is true for a rise in the share of persons aged 25-64 with pre-primary, primary or lower secondary education attainment, i.e. a rise in the share of such persons is associated with a rise in the poverty rate.

According to the results, none of the variables employed in the model has statistically significant indirect impacts. As already mentioned, the spatially lagged coefficients' estimates indicated statistically significant indirect effects, but in fact those are not statistically significant.

Summing up, the average direct effects and average indirect effects yield statistically significant positive average total impacts of education and negative average total impacts of income. The results further indicate a statistically significant average total impact of long-term unemployment on the at-risk-of-poverty rate in 2009. This is due to the direct impact size of the rise in unemployment in 2009.

Taking into account the time period (the pre-crisis year 2007 and the crisis years 2008 and 2009), certain changes appear in the estimated impacts. The size of the direct impacts of education and unemployment decreased between 2007 and 2008 and increased between 2008 and 2009, while the increase in the size of the long-term unemployment impact is significantly higher than the increase in the low education impact. As for the average direct impact of income, its size (in absolute terms) increased over the whole survey period and rose by more than 20 per cent between 2007 and 2009.

On the other hand, taking into account spillover effects, the size of the total average impacts (in absolute terms) decreased in the case of the low education level as well as disposable income between 2007 and 2009. The size of the long-term unemployment rate's direct average impact rose by almost 75 per cent between 2007 and 2009, and became statistically significant.
This might be explained by the rise in the longterm unemployment rate and the at-risk-of-poverty rate between 2008 and 2009, and unemployment is considered one of the most important factors of poverty. As for the spillover effects, the results propose an interesting finding. The total average impacts of the low education level, longterm unemployment and disposable income were stronger than the direct average impacts in 2007 and 2008. Then the situation changed and the total average impacts became weaker than the direct average impacts in 2009. This might be associated with the changed overall economic conditions in the European Union and its regions with respect to the consequences of the economic crisis in Europe.

The results indicate that the space matters in explaining poverty. Analysing poverty (similarly to other economic phenomena) without taking space into account results in a loss of important information concerning space.

Like every piece of research, the present study has its shortcomings. The relativity of poverty concept is one of its important limitations. Crossnational or cross-regional comparisons based on relative poverty measures are quite complicated and do not necessarily reflect the differences among countries or regions. The availability of data at the regional level is the most important limitation of poverty analyses. Many of the EU countries do not publish poverty data at the regional level (and many of them do not publish the variable "region" in the micro-data set), which makes poverty analyses at the regional level very difficult. On the other hand, we have to be aware of the shortcomings of regional data based on a limited number of observations resulting in biased estimates. Taking into account the heterogeneity across the EU regions, the availability of suitable data on poverty at the regional level is crucial for performing quality analyses as well as for policy implications.

Acknowledgement and Disclaimer

This work was supported by the Slovak Scientific Grant Agency as part of the research projects VEGA 1/0127/11 Spatial Distribution of Poverty in the European Union and VEGA 2/0004/12 Paradigms of the Future Changes in the 21st Century (Geopolitical, Economic and Cultural Aspects). The EU-SILC data sets were made available for the research on the basis of contract No. EU-SILC/2011/33, signed between the European Commission, Eurostat and the Technical University of Kosice. Eurostat has no responsibility for the results and conclusions, which are those of the researcher.

\section{References}

1. Ravallion M. (2009). The Crisis and the World's Poorest. Development Outreach, 11, 3, 16-18.

2. Pressman S., Scott R. (2009). Consumer debt and the measurement of poverty and inequality in the USA. Review of Social Economy, Vol. 67, 2,127-148.

3. Copeland P., Daly M. (2012). Varieties of poverty reduction: Inserting the poverty and social exclusion target into Europe 2020. Journal of European Social Policy, Vol. 22, 3, 273-287.

4. Bobkov V. N., Veredyuk O. V. (2013). Inequality of living standards in Russia: Internal and international context (the early 1990s and the 2000s). Economy of Region. 3, 62-70. 
5. Ravallion M. (1992). Poverty Comparisons: A Guide to Concepts and Methods. Washington DC: The World Bank. ISSN 02534517.

6. Duclos J. Y., Araar A. (2006). Poverty and Equity: Measurement, Policy and Estimation with DAD. New York: Springer. ISBN 978-0387-33318-2.

7. Sen A. K. (1984). The Living Standard. Oxford Economic Papers, New Series. Vol 36, Supplement: Economic Theory and Hicksian Themes, 74-90.

8. Sen A. K. (1999). Commodities and Capabilities. New Delhi: Oxford University Press, 1999. ISBN 0-19-565038-7.

9. Zelinsky T. (2010). Analysis of Poverty in Slovakia based on the Concept of Relative Deprivation. Politicka ekonomie. Vol. $58,4,542-565$.

10. Forster M., Jesuit D., Smeeding T. (2003). Regional Poverty and Income Inequality in Central and Eastern Europe. WIDER Discussion Papers. World Institute for Development Economics (UNU-WIDER), No. 2003/65.

11. Betti G. et al. (2005). Comparative Indicators of Regional Poverty and Deprivation: Poland versus EU-15 Member States. Comparative Economic Analysis of Households' Behaviour (CEAHB): Old and New EU Members. Warsaw 30 September - 1 October, 2005.

12. Verma V., Betti G., Natilli M., Lemmi A. (2006). Indicators of Social Exclusion and Poverty in Europe's Regions. Working Paper n. 59. Siena: Department of Quantitative Methods, University of Siena.

13. Quintano C., Castellano R., Punzo G. (2007). Estimating Poverty in the Italian Provinces using Small Area Estimation Models. Metodoloski zvezki, Vol. 4, 1, 37-70.

14. Pirani E., Schifini D’Andrea, S. Vermunt J.K. (2009). Poverty and social exclusion in Europe: differences and similarities across regions. 26 IUSSP Conference, Marrakech.

15. Betti G. et al. (2012). Subnational indicators of poverty and deprivation in Europe: Methodology and applications. Cambridge Journal of Regions, Economy and Society. Vol. 5, 1, 129-147.

16. R Core Team (2012). R: A language and environment for statistical computing. R Foundation for Statistical Computing, Vienna, Austria. ISBN 3-900051-07-0.

17. Bivand R. et al. (2013). spdep: Spatial dependence: weighting schemes, statistics and models. R package version 0.5-56.

18. Keitt T. H. et al. (2013). rgdal: Bindings for the Geospatial Data Abstraction Library. R package version 0.8-4.

19. Lewin-Koh N. U. (2013). maptools: Tools for reading and handling spatial objects. R package version 0.8-22.

20. Soetaert K. (2012). shape: Functions for plotting graphical shapes, colors. R package version 1.4.0.

21. LeSage J., Fischer M. M. (2008). Spatial Growth Regressions: Model Specification, Estimation and Interpretation. Spatial Economic Analysis. Vol. 3, 3 (2008), 275-304.

22. LeSage J., Pace R. K. (2009). Introduction to Spatial Econometrics. New York: CRC Press, 2009. ISBN 978-1-42006424-7.

23. Fischer M. M. et al. (2010). The impact of human capital on regional labour productivity in Europe. In Fischer, M. M., Getis A. (eds): Hadbook of Applied Spatial Analysis. Springer, Berlin, Heidelberg and New York, pp. 583-597.

24. Fischer M. M., Wang J. (2011). Spatial Data Analysis: Models, Methods and Techniques. Berlin: Springer, 2011. ISBN 9783-642-21719-7.

\section{Information about the author}

Zelinsky Tomas (Kosice, Slovakia) - PhD, Associate Professor, Department of Regional Science and Management, Faculty of Economics, Technical University of Kosice (32, Nemcovej, Kosice, 04001 Slovakia, e-mail: tomas.zelinsky@tuke.sk). 